\title{
NEUROART/NEUROARTE
}

\section{Caricatura e cefaleia}

\section{Caricature and headache}

\author{
Daniella Araúio de Oliveira', Louana Cassiano da Silva², Dayzene Freitas da Silva', \\ Gabriela Almeida da Silva', Mariana Luiza da Silva Queiroz', Marcos Antônio de Oliveira Filho², \\ Rafael Costa ${ }^{2}$, Marcelo Moraes Valença ${ }^{2}$ \\ Departamentos de Fisioterapia' e Neuropsiquiatria², Universidade Federal de Pernambuco, \\ Cidade Universitária, Recife, PE, Brasil
}

Oliveira DA, Silva LC, Silva DF, Silva GA, Queiroz ML, Oliveira Filho MA, et al. Caricatura e cefaleia. Headache Medicine. 2015;6(1):24-6

\section{RESUMO}

Os autores comentam sobre o uso de caricatura para representar uma pessoa sofrendo de cefaleia e publicam uma caricatura realizada por um artista de praça da cidade de Goiânia, Goiás, representando uma mulher jovem com enxaqueca.

Palavras-chave: Migrânea; Arte; Cefaleia; Caricatura

\section{ABSTRACT}

The authors comment on the use of caricature to represent a migraine sufferer and show a caricature of a woman with migraine drawn by an artist from Goiânia, Goias State, Brazil.

Keywords: Migraine; Art; Headache; Caricature

\section{INTRODUÇÃO}

Caricatura é uma forma de arte onde se preconiza o exagero dos traços de um desenho com finalidade de acentuar aspectos importantes da gravura. "Caricare" em italiano significa "carregar", "acentuar", no sentido de exagerar, aumentar algo em proporção, ou seja, é o desenho de uma personagem ou situação sociopolítica, acentuado suas características, circunstâncias, gestos, hábitos e vícios, de forma geralmente humorística. ${ }^{(1)} \bigcirc$ termo foi utilizado pela primeira vez em 1646 para designar desenhos satíricos de Agostino Carracci que retratava personagens exóticos de Bolonha. ${ }^{(1,2)}$
Relatos especulam que a caricatura já era utilizada por povos antigos como os egípcios, gregos e romanos. ${ }^{(2)}$ Tais evidências têm sido encontradas em pinturas de vasos gregos, afrescos romanos em Pompéia e Herculano e em um papiro, no museu de Turim, que retrata o faraó Ramsés II com orelhas de burro. A primeira caricatura reconhecida como arte independente, hoje no museu de Estocolmo, data de 1600 e foi feita por Annibale Carracci, retratando um casal de cantores italianos. ${ }^{(2)}$ (Figura 1).

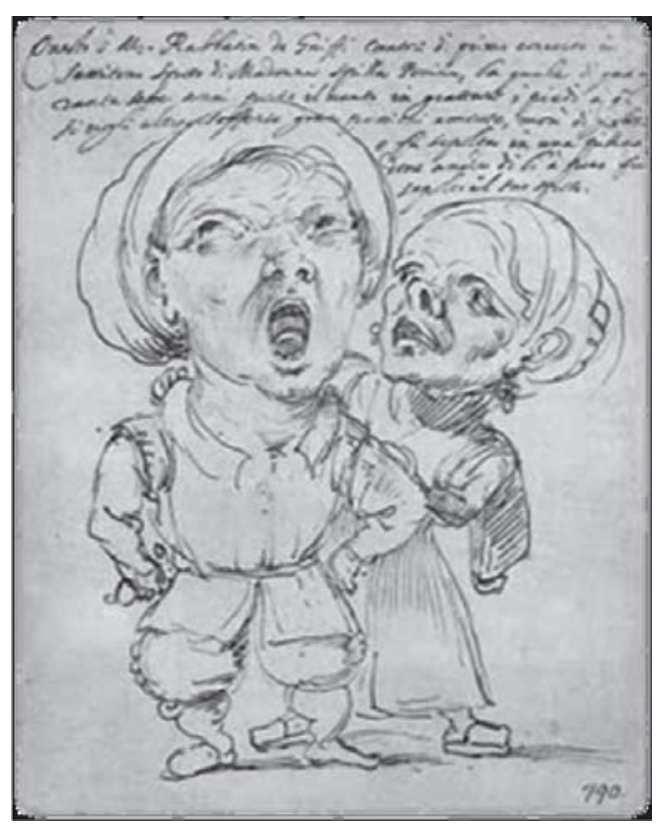

Figura 1. Desenho de Annibale Carracci retratando um casal de cantores italianos em 1600. 
De simples divertimento à importante atividade artística a caricatura influenciou e foi cultivada por grandes artistas como Bosch, Quentin Metsys, Leonardo da Vinci, Arcimboldo, Jacques Callot, Goya, Ensor e George Grosz. ${ }^{(2)}$

No Brasil, apesar de Antônio Francisco Lisboa, famoso escultor e arquiteto mineiro do século XVIII, mais conhecido como Aleijadinho, ser citado como o primeiro a utilizar a caricatura em uma escultura de São Jorge com o dragão, retratando os traços do coronel José Romão, pessoa com a qual tinha inimizade; o reconhecido iniciador da caricatura no Brasil foi Manuel de Araújo Porto Alegre que publicou, anonimamente, no
Jornal do Commercio em 14 de dezembro 1837, uma sátira ao jornalista Justiniano José da Rocha, seu inimigo. ${ }^{(2)}$

Em várias partes do mundo, as caricaturas são utilizadas para expressar críticas sociais e sátiras políticas com objetivo de levar ao público seus aspectos mais cômicos, polêmicos ou agressivos. (3) $^{(3)}$ Destacam-se nesse aspecto o pintor Francisco de Goya, na Espanha, em "Os Caprichos de Goya", que é uma série de 80 gravuras que representa uma sátira da sociedade espanhola de final do século XVIII, sobretudo da nobreza e do clero(4) (Figura 2); e no Brasil o pernambucano, nascido em Recife, Péricles de Andrade Maranhão com o perso-

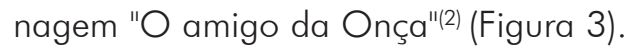
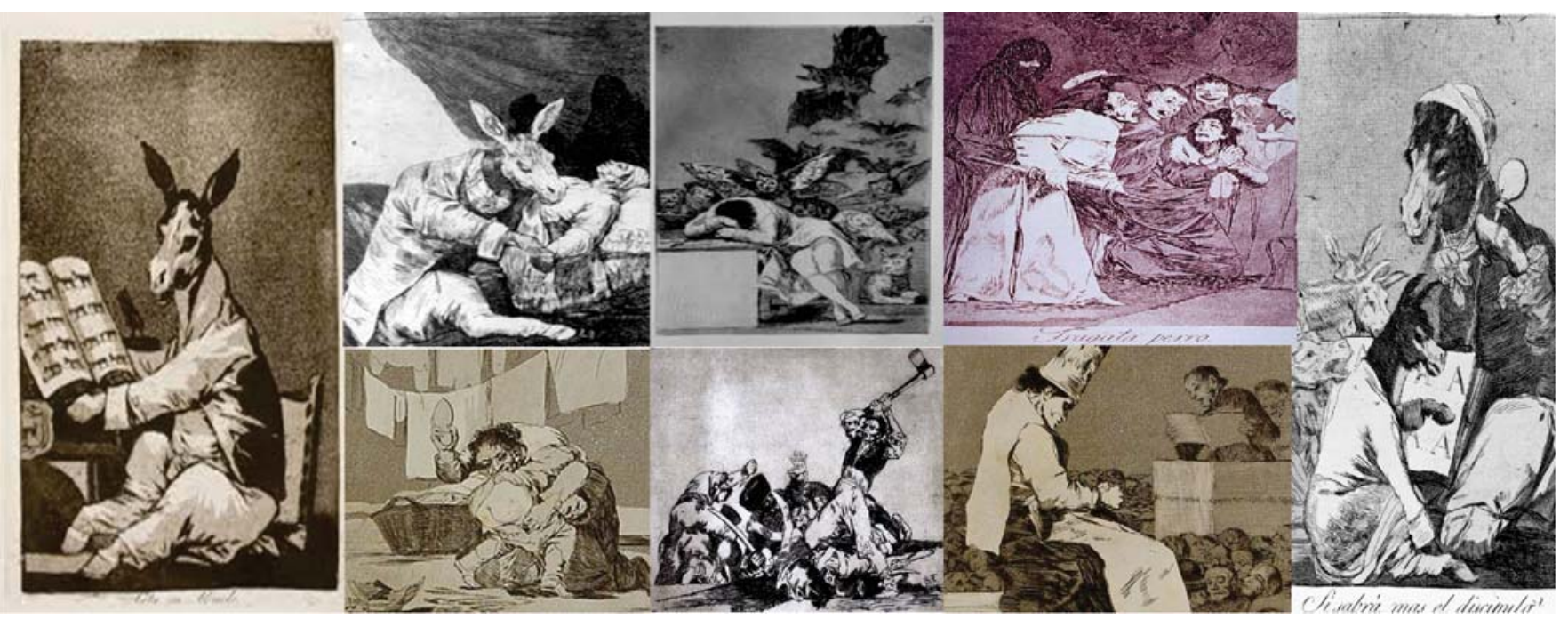

Figura 2. Oitos imagens da série de 80 gravuras de "Os Caprichos de Goya" - caricaturas do pintor espanhol Francisco de Goya. Nestas gravuras o artista combinava o ridículo, a extravagância e a fantasia, criticando os vícios e erros da sociedade espanhola da época.



Figura 3. Personagem do artista Péricles de Andrade Maranhão. Sempre satírico, irônico e crítico, o personagem "O amigo da onça" aparecia desmascarando seus interlocutores ou colocando-os em situações embaraçosas.
Além do conteúdo sociopolítico, a caricatura dá ênfase a expressões e sentimentos exacerbados, usando formas modificadas do corpo humano, principalmente do rosto, bem como de animais, sempre com intuito de impressionar ou influenciar o grande público. ${ }^{(5)}$

Em 2013, durante o XXVII Congresso Brasileiro de Cefaleia, realizado em Goiás, foi solicitado a um caricaturista encontrado em uma das praças de Goiânia, que desenhasse uma pessoa com crise de cefaleia (Figura 4). A caricatura mostra essa impressão da dor, embora o artista houvesse afirmado que nunca havia sentido dor de cabeça. $\bigcirc$ que chama atenção da imagem é a face de sofrimento, comum em pacientes com crises de forte intensidade, como ocorre na migrânea, as estrelas e raios podem ser interpretadas como dor unilateral, pulsátil e com possível aura visual. Os olhos semifechados podem indicar uma possível fotofobia. 


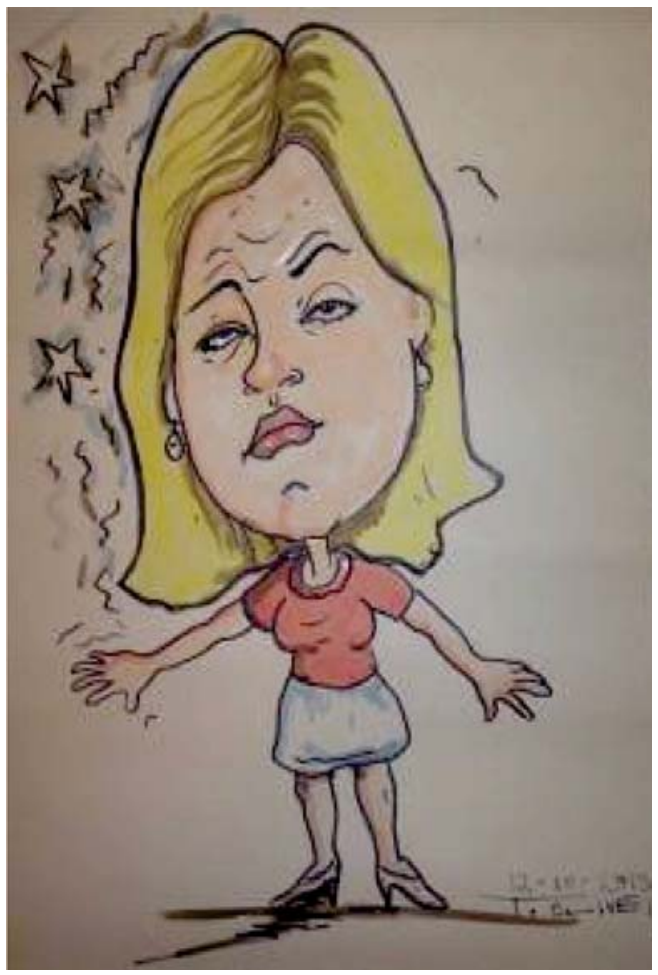

Figura 4. Caricatura representando uma mulher com cefaleia. Curiosamente, a caricatura lembra uma das pessoas presentes no momento que o artista realizava seu trabalho, a Louana Cassiano da Silva, com exceção do cabelo louro. Contudo, não sabemos se esse fato é verídico. Apenas que ela sofre muito com suas crises de enxaqueca. Imagem do artista T. Oliveira, em Goiás, 2013.

Neste artigo, os autores buscaram revisar a utilização da caricatura como forma de atividade artística, ao longo da história, para destacar situações cotidianas. As caricaturas são amplamente utilizadas como sátira política e crítica social, sendo divulgadas em jornais, revistas e manifestos. Além disso, elas podem ser utilizadas como meio de entretenimento, por alguns profissionais, que realizam a caricatura de determinada pessoa ou situação momentâneas, exagerando certos aspectos relevantes com intenção de captar detalhes da personalidade ou impressões de sentimentos.

Hoje podemos encontrar na internet muitos exemplos de caricaturas representando um o sofrimento de uma pessoa com cefaleia.

\section{REFERÊNCIAS}

1. Wikipédia. Caricatura [acesso em 28 fev 2015]. Disponível em: http://pt.wikipedia.org/wiki/Caricatura

2. Portal Endiv - uma janela para o mundo. Caricatura - história e características [acesso em 28 fev 2015]. Disponível em: http:/ /emdiv.com.br/arte/enciclopediadaarte/685-caricaturahistoria-e-caracteristicas.html
3. Siqueri MS. Caricatura política e a produção de discursos derrisórios. Cuiabá. Dissertação [Mestrado em Estudos de Linguagem] - Universidade Federal de Mato Grosso; 2006.

4. Wikipédia. Los caprichos [acesso em 28 fev 2015]. Disponível em: http://pt.wikipedia.org/wiki/Los_caprichos

5. Mendes AIF. Caricatura e reconhecimento de faces. Ribeirão Preto. Tese [Doutorado em Ciências, Área Psicobiologia] Universidade de São Paulo; 2007.

Correspondência

Daniella Araújo de Oliveira

Av. Jorn. Anibal Fernandes, s/n, Cidade Universitária

50740-560 - Recife, PE, Brasil

Fone: (55-81) 21268937, Fax (55-81)21268491

E-mail: sabino_daniella@ig.com.br 